\title{
EFFECT OF LASER AND CHEMICAL SURFACE TREATMENT OF COBALT-CHROMIUM ALLOY ON ITS BOND STRENGTH WITH HEAT CURED ACRYLIC RESIN (COMPARATIVE LABORATORY STUDY)
}

\author{
Kamel M. Aboelsayed ${ }^{1} B D S$, Ossama A. Mahfouz ${ }^{2} P h D$, Omaima Aboulwafa ${ }^{3} P h D$, \\ Mohamed A. Hafez ${ }^{4} P h D$
}

\begin{abstract}
INTRODUCTION: Durability of the removable prostheses is dependent on strong adhesion between the metal framework and acrylic resin. Weak adhesion causes separation of the denture base from the metal framework. It was reported that Neodynium-doped yttrium aluminium garnet (Nd:YAG) laser surface treatment can be used to strengthen the bond between dental alloys and resins. Aryldiazonium salts have been used to create a strong chemical bond between dental alloys and polymers.

OBJECTIVES: To evaluate and compare the effect of Nd:YAG laser surface treatment and Aryldiazonium salts of cobalt chromium (Co-Cr) alloy on its bond strength with heat cured acrylic resin. Also, to analyze the metal-resin interface at a high-resolution level after laser and Aryldiazonium salts surface treatments.

MATERIALS AND METHODS: Ten healthy adult white Albino New Zealand rabbits, after creating two osseous defects in the right femur in each. The defects (upper and lower) were divided in to two groups according to the material used for filling: Group A (Control): in the upper defect, bone graft only was added in the lateral side of the right femur.

Group B (Study): in the lower defect, MPM was added in the lateral side of the right femur. After 2 \&8 weeks respectively postoperatively, sacrification of the rabbits was done.

RESULTS: Data collected from histological results revealed that MPM enhanced bone formation where increased amount of new bone formation was observed in the study group in relation to the control group. At the end of the experimental period, the defect area was almost filled with mature bone which occupied a greater surface area in the study group. Histomorphometric analysis revealed that there was increase in the mean percentage of bone surface area in the study group in comparison to the control group. This increase was statistically significant in the 8 weeks period.

CONCLUSIONS: The bond strength between heat cured acrylic resin and alloy can be increased by Aryldiazonium salts application and laser surface treatment.

KEYWORDS: Dental prosthesis, Aryldiazonium salts, Nd:YAG laser, Co-Cr alloy, heat cured acrylic resin.

1. B.D.S. Removable Prosthodontics Department, Faculty of Dentistry, Alexandria University.

2. Professor in Removable Prosthodontics Department, Faculty of Dentistry, Alexandria University.

3. Professor in Pharmaceutical Chemistry Department, Faculty of pharmacy, Alexandria University.

4. Assistant professor in Laser Science and Interactions Department, National Institute of Laser Enhanced Science, Cairo University.
\end{abstract}

Corresponding author:

E-mail: kamel.aboelsayed@yahoo.com

\section{INTRODUCTION}

Complete and partial tooth loss is associated with reductions in physical, psychological and social functions, ability to chew, and potential harm to general health. Therefore, rehabilitation of stomatognathic system by removable prosthodontics can be considered satisfactory, when prosthesis can give effective and efficient service to the patient (1).

Most removable prostheses were constructed of cast metal base and acrylic resin which was processed to retain artificial teeth, restoring lost tissue contours, and enhancing esthetics. The metal framework commonly constructed of cobalt chromium alloys (Co-Cr) because of its adequate strength, rigidity, resistance to corrosion, lightness in weight, and low cost. Heat polymerized acrylic resin is also generally utilized as a denture base polymer for removable prostheses. It was chosen based on availability, dimensional stability, handling characteristics, and color compatibility with the oral tissues (2).

The bonding between the metal components and the denture base resin plays an important role in the longevity of the prosthesis. In the oral cavity, the bond between acrylic resin and metal framework should withstand continuous exposure to occlusal forces, constant flow of the saliva, and temperature variations that occur during ingestion of food and drinks (3).

Weak adhesion and lack of chemical bond cause separation of the denture base from the metal framework. Discrepancies in the coefficient of thermal expansion among these components may promote this space, leading ultimately to microleakage of saliva. Furthermore, microleakage in the area of internal and external finishing lines results in discoloration, deterioration of denture base material, and introduction of potentially pathogenic 
microorganisms that may be harbored within the crevice and contribute to an adverse soft tissue response (4).

Metal-resin bonding systems may be categorized as mechanical, chemical or a combination of both. Failure of the metal-resin interface occurs when forces exceed the capacity of the bonding mechanisms. The bonding between the metal framework and the denture resin is critical; especially in situations such as limited interridge space, short span edentulous area, and where excessive functional forces are anticipated (5).

Conventional methods of attaching the denture base resin to the metal framework include loops, mesh, beads, nail heads, and struts, which provide macromechanical retention. The major disadvantage of macromechanical retention between the denture base resin and the metal framework is poor marginal sealing, which is not sufficient to prevent microleakage (6).

Because of the disadvantages of macromechanical resinmetal attachment, microscopic retentive designs were suggested to improve bonding of resin and metal, such as sandblasting the metal surface, electrolytic and chemical etching (7), and laser surface treatment(8).

Laser surface treatment seems to be a very promising method because it is fast, precise, and nearly damage-free material processing $(5,9)$. Since the development of the first working laser by Maiman in 1960 (10), advances in this technology have resulted in using laser in many fields of dentistry. Neodynium-doped yttrium aluminium garnet (Nd:YAG) lasers are solid-state lasers used in (a) prosthetic dentistry to modify feldspathic ceramic surfaces and to improve titanium- porcelain bonding, (b) surgery on intraoral soft and hard tissues, and (c) endodontics (11).

Murray et al (12) reported that laser etching of a dental alloy can increase the bond strength between the alloy and resin composite. Kim and Cho (13) demonstrated that $\mathrm{Nd}$ :YAG laser etching improved the bond strength of a titanium substrate to porcelain. Collectively, the results of these studies showed that $\mathrm{Nd}$ :YAG laser surface treatment can be used to strengthen the bond between dental alloys and porcelain or resins (14).

Further improvement in the bonding strength between the denture base resins to the metal framework is still needed to prevent debonding and reduce microleakage at the resin-metal interface. Therefore, resin-metal bond can be strengthened by adding a chemical link between the denture base resin and the metal framework (15).

Many techniques and materials have been used to enhance chemical bonding between metal and acrylic resin, such as adhesive resin 4-methacryloylexy ethyl trimellitate anhydride (4-META), Silicoater system, and adhesive metal primers (16).

A novel method for creating a strong chemical bond between the denture base resin and the metal framework for dental prostheses is developed based on Diazonium chemistry (17). Aryldiazonium salts have been used to modify material surfaces for many applications. Diazonium ions can be produced from aromatic amines and grafted onto almost any surface, including metals, glass, and carbon (18).

There are limited data available on Nd:YAG laser surface treatment and Aryldiazonium salts application for improving the metal-resin bond. Hence, the objective of this study is to evaluate and compare the effect of Nd:YAG laser surface treatment and Aryldiazonium salts of Co-Cr alloy on its bond strength with heat cured acrylic resin.

\section{MATERIALS AND METHODS}

The following materials were used in this study:

1.Co-Cr alloy (MAGNUM H50, MESA di Sala Giacomo, Italy).

2.Heat cured Poly-methyl methacrylate (PMMA) (Acrostone Co. Ltd. Egypt).

3.Aryldiazonium salts which was prepared from [Pphenylenediamine (PPD), sodium nitrite (NaNO2), sodium dodecyl sulfate (SDS), benzoyl peroxide (BP), and iron powder $(\mathrm{Fe})]$.

4.Hydrochloric acid ( $\mathrm{HCl})$ of $0.5 \mathrm{M}$ concentration (ElGomhouria CO, for chemicals \& medical Supplies, Egypt).

Seventy two tensile bar specimens were prepared in such a way that half of the bar was made of Co-Cr alloy and the other half made of heat cured acrylic resin. The size, design and dimensions of the specimens complied with those of the British standardization (Figure 1) (19).

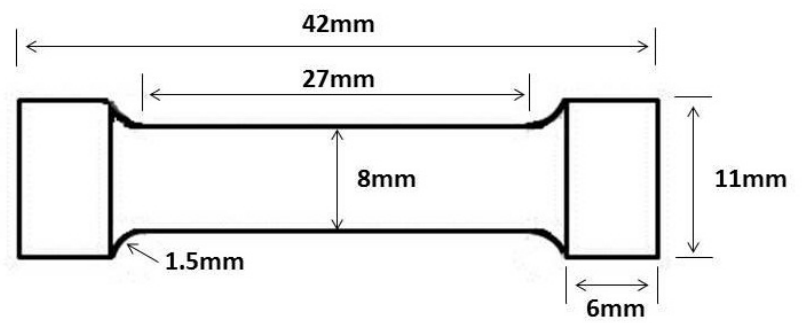

Figure 1: Diagram showing the dimensions of the tensile bar specimen.

\section{Preparation of the metallic samples:}

Seventy two wax patterns were fabricated using special copper mold (corresponding to half of the tensile bar specimen), which were then invested and casted in Co-Cr alloy (Figure 2).

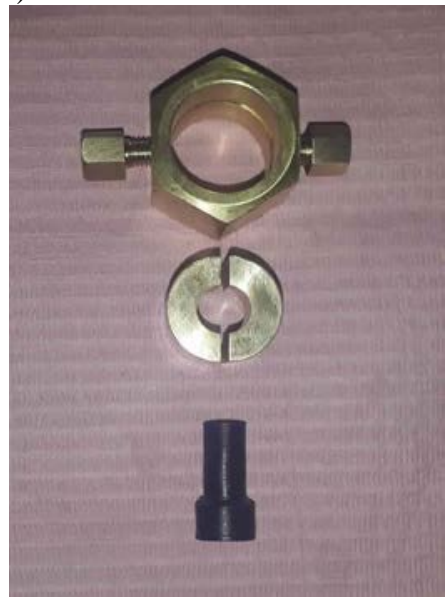

Figure 2: Wax pattern corresponding to half of the tensile bar specimen and the split copper mold.

After casting, all visible protruding metal fibers on the surface of each specimen were removed with a bur, finished and polished. Each specimen was then cleaned ultrasonically in distilled water for 60s (10).

\section{Sandblasting of the metallic samples:}

The surface of each cast specimen was then sandblasted using 110 -mm aluminum oxide $\left(\mathrm{Al}_{2} \mathrm{O}_{3}\right)$ at $0.25 \mathrm{MPa}$ for $30 \mathrm{~s}$, and then cleaned with water in an ultrasonic bath for $10 \mathrm{~min}$ (14). 
After sandblasting, the cast specimens were then randomly assigned to three equal groups according to the surface treatments:

- Group I: sandblasting only (control group).

- Group II: sandblasting + Aryldiazonium salts.

- Group III: sandblasting + Nd:YAG laser.

\section{Surface preparations}

\section{Aryldiazonium salts application:}

The surface treatment of metal samples using Aryldiazonium salts was performed in a two steps protocol (priming and adhesive). Both steps were carried out in acidic DW solution at $\mathrm{pH} \leq 2$, since Diazonium cations are stable at $\mathrm{pH} \leq 2.5$, at room temperature in a simple glass beaker (17).

The priming step was conducted as follows:

1. PPD (0.054 g) and NaNO2 (0.034 g) were dissolved in a glass beaker containing $10 \mathrm{ml}$ of $0.5 \mathrm{M} \mathrm{HCl}$.

2. The solution was ultrasonicated for 5 min to produce Aryldiazonium salt.

3. The metallic samples were immersed in the previous solution and Fe powder (0.250 g) was added as a reducing agent to produce Aryl radicals (the resultant Aryl radicals are nominated Polyaminophenylene).

4. The samples were left to react for $15 \mathrm{~min}$.

5. Ultrasonicating the samples in DW and acetone for 5 min.

The previously mentioned steps (priming) lead to spontaneous grafting of a Polyaminophenylene (PAP) layer on the metallic samples. These samples are referred to as metal-PAP from here onwards.

The second (adhesive) step to optimize the adhesion of MMA to metal-PAP samples was conducted as follows:

1) $\mathrm{NaNO}_{2}(0.034 \mathrm{~g})$ was dissolved in $10 \mathrm{ml}$ of $0.5 \mathrm{M} \mathrm{HCl}$.

2) The metal-PAP samples were introduced in the solution.

3) Adding Fe powder (0.250 g) to the solution.

4) Surfactant (SDS, $0.026 \mathrm{~g}$ ) was added along with the monomer (MMA) to help emulsify the hydrophobic monomer.

5) The reaction was allowed to continue for $15 \mathrm{~min}$ in the ultrasonic bath.

6) An initiator (BP) was added after the 15 min sonication stage to accelerate the polymerization reaction on the metallic surface.

7) The reaction was allowed to continue for another $30 \mathrm{~min}$ on the bench top; during this period the monomer polymerized forming a layer of PMMA on the metallic surface.

8) Finally, the samples were thoroughly rinsed with acetone, and then ultrasonicated in DW and acetone for $5 \mathrm{~min}$ in order to discard any ungrafted matter.

\section{Laser surface treatment:}

The sandblasted Group III was treated with an Nd:YAG laser with a wavelength of $1,064 \mathrm{~nm}$. The parameters used for laser surface treatment were $1.30 \mathrm{KV}$ potential, $84.4 \mathrm{~mJ}$ energy, $1 \mathrm{~Hz}$ frequency, and 10 pulses for every spot.

The laser beam was directed perpendicular to the surface of the specimen. This laser beam was collimated using optical lens with $10 \mathrm{~cm}$ focal length. The specimen was mounted on a scaled wheel at a distance of $10 \mathrm{~cm}$ from the lens (focal length). A laser spot was made every five degrees on the scale to form a continuous circular line on the periphery of the specimen (14).

Bonding of heat cured PMMA to Co-Cr alloy specimens: Full size tensile bar specimens were constructed by milling from copper material and invested in dental stone in a conventional dental flask (three per flask). After dental stone has set, the copper specimens were removed carefully from the flask, as they left empty mold cavities corresponding to the full size of the tensile bar specimens. After that, the surface treated alloy specimens were placed in the mold cavities to fill half of the space (Figure 3).

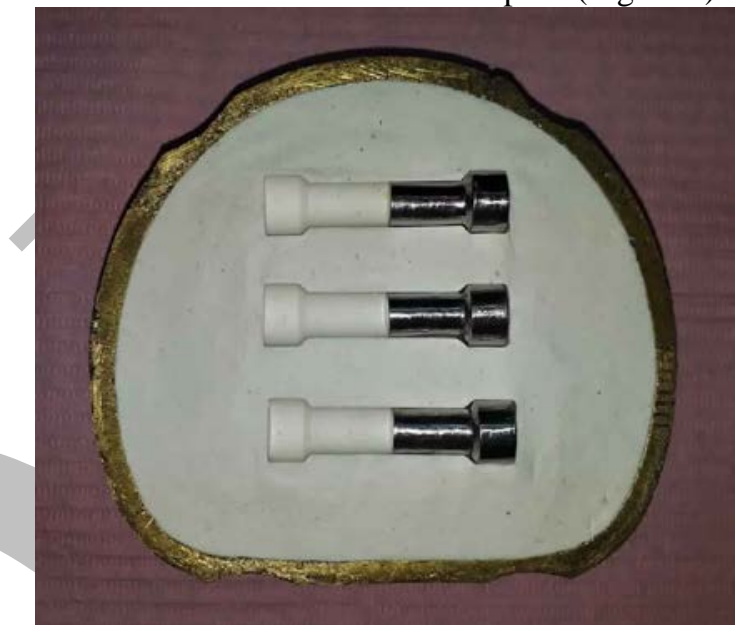

Figure 3: The surface treated alloy specimens placed in the mold cavities.

Heat cured PMMA was prepared according to the manufacturer's instructions, packed into the stone cavity, and then polymerized in denture flasks. Once polymerization completes, the denture flask was allowed to cool slowly at room temperature before deflasking of the specimens (Figure 4) (20).

Figure 4: Heat cured PMMA-alloy specimens.

\section{Determination of the bond strength:}

The tensile bond strength of each heat cured PMMA-alloy specimen was determined in air at room temperature using Universal testing machine (Figure 5). 


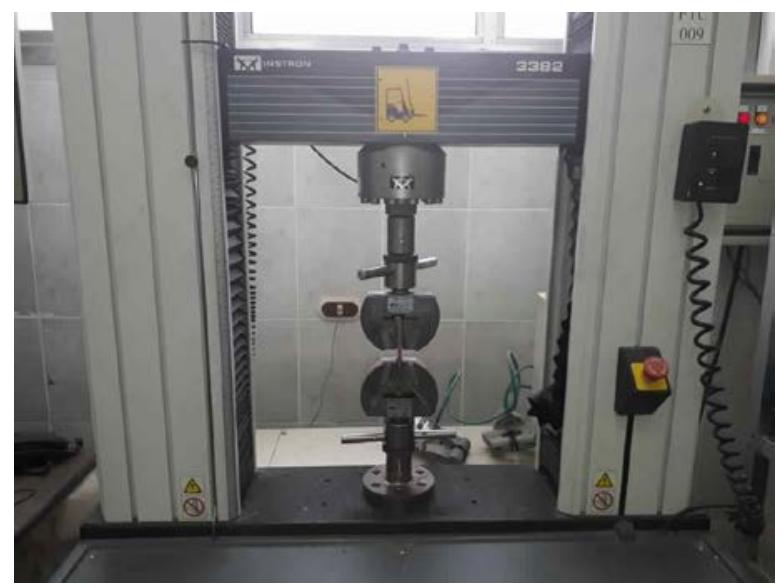

Figure 5: Universal testing machine.

All specimens were mounted on the Universal testing machine and were debonded in tension at a crosshead speed $0.5 \mathrm{~mm} \backslash \mathrm{min}$ until the specimen failed. The load in kilograms at which the specimens were debonded was recorded.

Tensile bond strength was expressed by dividing the load in kilograms by the surface area of the bonded surface of the tensile bar in centimeters square.

$\underset{(\mathrm{S})=}{\text { Bond strength }} \frac{\text { Load at failure }}{\text { Surface area }} \mathrm{Kg} \mathrm{cm}{ }^{2}$

Surface area $=\pi r^{2}=3.14 \times(0.4)^{2}=0.5024 \mathrm{~cm}^{2}$ $\pi=3.14 \quad \mathrm{r}=$ radius of the cross sectional surface of the tensile bar $=0.4 \mathrm{~cm}$.

Tensile bond strength values in $\mathrm{Kgs} \backslash \mathrm{cm}^{2}$ were converted into Mega Pascal by manipulating $\times 0.0980665$. Then, the results were tabulated and statistically compared (17).

\section{Scanning electron microscopy:}

Scanning electron microscope images were taken to analyze the interface between heat cured PMMA to Co-Cr alloy at the surface of the treated side. Images were taken at specific position marked in all specimens.

The specimens were gold coated using a sputter coating machine. Then, they were mounted on aluminum table using a double sided tape to stabilize the specimens for viewing in the SEM chamber (21).

\section{Statistical analysis}

Data were analyzed statistically using a computerized statistical software program (IBM SPSS software package version 20.0. (Armonk, NY: IBM Corp)). The differences in the mean tensile bond strength were analyzed using $F$ test (ANOVA), while comparison between the mean values of the gap was analyzed using Kruskal-Wallis test. The Pairwise comparison between each two groups was done using Post Hoc Test (Tukey). Significance of the obtained results was judged at the $5 \%$ level.

\section{RESULTS}

\section{1- Evaluation of the tensile bond strength}

The mean tensile bond strength (Mega Pascal) between PMMA and the Co-Cr alloy after the various surface treatments are summarized in Table (1) which was as follows group I (1.624), group II (3.288) and group III (3.432).
Table (1): Comparison between the three study groups according to tensile bond strength (Mega Pascal)

\begin{tabular}{|c|c|c|c|c|c||}
\hline $\begin{array}{c}\text { Tensile bond } \\
\text { strength } \\
\text { (Mega } \\
\text { Pascal) }\end{array}$ & $\begin{array}{c}\text { Group I } \\
\text { (n= 24) }\end{array}$ & $\begin{array}{c}\text { Group II } \\
\text { (n= 24) }\end{array}$ & $\begin{array}{c}\text { Group } \\
\text { III } \\
(\mathbf{n}=\mathbf{2 4})\end{array}$ & F & p \\
\cline { 1 - 4 } Min. - Max. & $\begin{array}{c}0.642- \\
3.727\end{array}$ & $\begin{array}{c}2.072- \\
4.452\end{array}$ & $\begin{array}{c}2.295- \\
4.712\end{array}$ & & \\
\cline { 1 - 4 } Mean \pm SD. & $\begin{array}{c}1.624 \pm \\
0.789\end{array}$ & $\begin{array}{c}3.288 \pm \\
0.580\end{array}$ & $\begin{array}{c}3.432 \pm \\
0.672\end{array}$ & $51.527^{*}$ & $<0.001^{*}$ \\
\hline Median & 1.354 & 3.244 & 3.306 & & \\
\hline
\end{tabular}

F: F for ANOVA test, Pairwise comparison bet. each 2 groups was done using Post Hoc Test (Tukey)

$\mathrm{p}$ : $\mathrm{p}$ value for comparing between the three groups

$*$ : Statistically significant at $p \leq 0.05$

Group I: Sandblasting

Group II: Aryl diazonium salts

Group III: ND: YAG Laser

The mean tensile bond strength of laser surface treatment of the sandblasted surface was higher than that after applying Aryldiazonium salts to the sandblasted surface. Also, we found that the tensile bond strengths were the highest when the sandblasted surfaces were treated with $\mathrm{Nd}$ :YAG laser, and lowest in the sandblasted-only surfaces.

By analyzing the data using one way ANOVA test, we found that all groups have significantly higher mean values for tensile bond strength in comparison with the control group $(\mathrm{p}<0.05)$.

Table (2) showed the results of Post Hoc Test (Tukey) which compared between each two groups. A significant differences in the tensile bond strength were found between group I and the other two groups II\&III $(p<0.05)$.While, non-significant difference in the tensile bond strength was found between group II and group III ( $\mathrm{p}>0.05$ ).

Table (2): Comparison between each two groups according to tensile bond strength (Mega Pascal)

\begin{tabular}{||c|c|c|}
\hline Groups & p & Significance \\
\hline Group I - Group II & $<0.001^{*}$ & Significant \\
\hline Group I - Group III & $<0.001^{*}$ & Significant \\
\hline Group II - Group III & 0.749 & Non-significant \\
\hline
\end{tabular}

Comparison between each 2 groups using Post Hoc Test (Tukey)

$\mathrm{p}$ : $\mathrm{p}$ value for comparing between each 2groups

$*$ : Statistically significant at $\mathrm{p} \leq 0.05$

Group I: Sandblasting

Group II: Aryl diazonium salts

Group III: ND: YAG Laser

\section{2- Scanning electron microscopy}

Scanning electron microscope (SEM) images showed that group I (sandblast) specimens exhibited obvious wide space or gap at the interface between heat cured PMMA and CoCr alloy. This gap was narrower in group III when the sandblasted surfaces were treated with Nd:YAG laser. On the other hand, this gap was dramatically reduced and in certain positions was not detected at the interface between heat cured PMMA and Co-Cr alloy after Aryldiazonium salts application (group II) (Figure 6). 


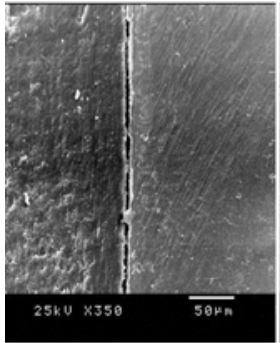

Sand blasting

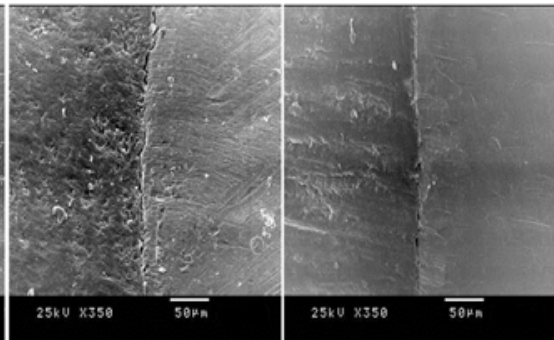

Laser surface treatment Chemical surface treatment
Figure 6: Scanning electron microscope (SEM) images showing the interface between heat cured PMMA to Co-Cr alloy in the three groups.

Table (3) showed the mean value of the gap (Micrometer) at the interface between heat cured PMMA and Co-Cr alloy which was as follows group I (4.69), group II (0.52) and group III (1.38).

By analyzing the data using Kruskal-Wallis test, a significant difference in the value of the gap was found between the three groups $(\mathrm{p}<0.05)$. Additionally, Post Hoc Test (Tukey) revealed a significant difference between each two groups $(\mathrm{p}<0.05)$.

Table (3): Comparison between the three study groups according to the value of the gap at the interface between heat cured PMMA and Co-Cr alloy (Micrometer).

\begin{tabular}{|l|l|l|l|l|c||}
\hline $\begin{array}{c}\text { Value of the } \\
\text { gap at the } \\
\text { interface }\end{array}$ & $\begin{array}{c}\text { Group I } \\
(\mathbf{n}=\mathbf{2 4})\end{array}$ & $\begin{array}{c}\text { Group II } \\
(\mathbf{n}=\mathbf{2 4})\end{array}$ & $\begin{array}{l}\text { Group } \\
\mathbf{I I I} \\
(\mathbf{n}=\mathbf{2 4})\end{array}$ & H & p \\
\hline Min. - Max. & $2.68-7.90$ & $0.0-1.20$ & $\begin{array}{l}0.85 \\
3.67\end{array}$ & & \\
Mean \pm SD. & $4.69 \pm 1.43$ & $0.52 \pm 0.44$ & $\begin{array}{l}1.38 \\
0.59 \\
1.22\end{array}$ & 59.968 & $<0.001$ \\
Median & 4.85 & 0.65 & $*$ \\
\hline Sig. bet. grps & $\mathrm{p}_{1}<0.001^{*}, \mathrm{p}_{2}<0.001^{*}, \mathrm{p}_{3}<0.001^{*}$ & & \\
\hline
\end{tabular}

$\mathrm{H}$ : H for Kruskal Wallis test, Pairwise comparison between each 2 groups was done using Post Hoc Test.

$\mathrm{p}$ : $\mathrm{p}$ value for comparing between the three groups

p1: p value for comparing between Group I and Group II p2: p value for comparing between Group I and Group III p3: p value for comparing between Group II and Group III

*: Statistically significant at $\mathrm{p} \leq 0.05$

Group I: Sandblasting

Group II: Aryl diazonium salts

Group III: ND: YAG Laser

\section{DISCUSSION}

The serviceability of the removable prosthesis is dependent on the bond strength at the resin-metal interface. The absence of bonding at the interface between the resin and metal can lead to loosening of the resin parts from the metal or discoloration of the margins between the resin and metal (22).

The difference in the coefficients of thermal expansion between the metal and resin contributes to the deterioration at the junction between the two materials. In addition, the polymerization shrinkage of heat-polymerized denture base resin affects the stress at the resin-metal interface (23).

Poor bonding at the metal-resin interface might cause microleakage leading to the ingress of oral fluids and microorganisms. The increased presence of microorganisms and plaque may cause an unfavorable response of the adjacent soft tissues especially in the region of marginal gingivae and discoloration of the acrylic resin base material. Also, incomplete fracture or total separation of the resin can occur. Improvement of acrylic resin to metal bond strength could enhance clinical success (24).

Significant research has focused on improving the bond between acrylic resin and metal to withstand the occlusal forces and endure the oral environment. The current study evaluated the effect of Nd:YAG laser surface treatment and Aryldiazonium salts of $\mathrm{Co}-\mathrm{Cr}$ alloy on its bond strength with heat cured acrylic resin.

The bond strength between the untreated polished Co-Cr alloy and heat cured PMMA was very low, indicating that the mechanical and chemical bonds were minimal. In fact it is extremely difficult to test the bond between a polished Co-Cr surface and PMMA, since the samples tend to fail very easily (25). This was the reason for choosing the sandblasting only as the control group.

The current study stated that the lowest value of the tensile bond strength was found in group I specimens. This may be attributed to poor adaptation of the resin to the complex surface topography of the Co-Cr alloy after sandblasting as found by Barclay et al (26). They offered two reasons for this latter conclusion. First, PMMA beads are unable to fully penetrate the roughened contact area on a Co-Cr alloy surface after sandblasting. Second, Alumina particles become embedded in the sandblasted Co-Cr alloy surfaces, and prevent the PMMA beads from flowing into the roughened surface.

The Diazonium chemistry method that we used to bind PMMA and dental alloys consisted of two steps in order to achieve covalent binding between metals and PMMA for applications in dental prostheses. The addition of an emulsifier, such as SDS, seemed to have improved this outcome of the reaction probably by increasing the availability of MMA to the treated surface because MMA is a hydrophobic monomer, slightly soluble in the aqueous solution used to modify the Co-Cr surface (27).

Heat cured PMMA polymerizes by free radical addition polymerization, which requires the presence of an initiator such as BP to start. Benzoyl Peroxide radicals react with MMA and create MMA radicals, which then propagate and polymerize layers of PMMA. In addition, BP seems to increase the reactivity of MMA and its polymerization rate on the PAP layer (28).

This study revealed that Aryldiazonium salts application increased the tensile bond strength between Co-Cr alloy and heat cured acrylic resin from 1.62 (control) to $3.29 \mathrm{MPa}$. Similarly, Alageel et al (17) found that the mechanical test results showed increasing the tensile bond strength between Ti and PMMA after Aryldiazonium salts application. Also, the shear bond strength between stainless steel wrought wire and PMMA was significantly higher when the wire was treated with Aryldiazonium salts than when it was left untreated. The resulting high bond strength indicates the formation of PMMA layer on the top of metal-PAP layer that can entangle very strongly with the PMMA chains casted on the sample (17).

The laser surface treatment seems to be a very promising approach. This relatively new technology bears a high potential for a fast, precise, and nearly damage-free material processing $(29,30)$.

The current study found that Nd:YAG laser surface treatment increased the tensile bond strength between CoCr alloy and heat cured acrylic resin from 1.62 (control) to 3.43 MPa. Similarly, Yilmaz et al (14) reported that the 
shear bond strength between PMMA and the Co-Cr alloy after Nd:YAG laser irradiation of the sandblasted surface was greater than that after applying primer to the sandblasted surface, and were twice as strong as the sandblasted only specimens.

In both studies, the surface of the alloy was first sandblasted and then laser irradiated. As a consequence, the penetrability of the PMMA beads was greater than that for the sandblasted surfaces, and could explain why the tensile bond strength of the group III specimens were higher than those of the Group I specimens (14).

Murray et al (31) stated that the tensile bond strength of the surfaces which had been both sandblasted and lased were significantly greater than surfaces with sandblasting or lasing alone. Imaging of these surfaces following preparation indicates that significant differences are present between the lased and sandblasted surface morphology, which are predominantly responsible for the differences in bond strengths.

Also, Cho and Jung (32) demonstrated that laser etching is an effective method for producing an appropriate surface roughness for titanium. Similarly, Wagner (33) reported that laser and electron-beam thermal treatments could be used for modification of the microstructure of titanium surfaces without contamination, providing optimal roughness.

On the other hand, Kim and Cho (13) detected that laser etching of titanium surfaces using an $\mathrm{Nd}$ :YAG laser demonstrated no significant difference in bond strength with low-fusing porcelain compared to airborne particleabrasion surfaces. They explained that surface pattern of the laser treated specimen appears smooth rather than rough, compared with the airborne-particle-abrasion groups that showed an irregular or hollowed appearance.

The Scanning electron microscope (SEM) examination of the specimens in the current study revealed the presence of wide gaps at the interface between heat cured PMMA and Co-Cr alloy in group I. On the other hand, narrower gaps were detected in group III specimens. This is attributed to the increase in the penetrability of the PMMA beads into the metal alloy surface after the laser surface treatment(14). These gaps were dramatically reduced and in certain positions were not observed at all in group II due to the presence of covalent binding between heat cured PMMA and Co-Cr alloy in the specimens treated by Aryldiazonium salts (17). To the best of our knowledge, no previous studies discussed this point for comparison of the results.

\section{CONCLUSION}

Within the limitations of this study, the following conclusions were drawn:

1. Laser and chemical surface treatments showed a significant improvement in the tensile bond strength between $\mathrm{Co}-\mathrm{Cr}$ alloy and heat cured acrylic resin.

2. No difference was detected in the bond strength between Co-Cr alloy and heat cured acrylic resin after laser and Aryldiazonium salts surface treatments.

3. Chemical surface treatment (Aryldiazonium salts) is better than laser surface treatment in improving the marginal seal at the finish line between metal and acrylic resin to decrease microleakage.

\section{CONFLICT OF INTEREST}

The authors declare that they have no conflicts of interest.

\section{REFERENCES}

1- Jones JA, Spiro A, Miller DR, Garcia RI, Kressin NR. Need for Dental Care in Older Veterans: Assessment of PatientBased Measures. Journal of the American Geriatrics Society. 2002;50:163-8.

2- Carr AB, Brown DT. McCracken's Removable Partial Prosthodontics. Twelfth ed.: Elsevier Health Sciences; 2011.

3- Kumar A, Singh K, Sarin A, Sachdeva S, Singh S. Evaluation and assessment of bonding of heat cure acrylic resin to cobalt-chromium alloy: Old ideas employing newer concepts. European Journal of Prosthodontics. 2014;2:1-10.

4. Ohkubo C, Watanabe I, Hosoi T, Okabe T. Shear bond strengths of polymethyl methacrylate to cast titanium and cobalt-chromium frameworks using five metal primers. The Journal of Prosthetic Dentistry. 2000;83:50-7.

5. Dewan H, Chohan H, Gujjari AK. The Effect of Metal Primer on the Shear Bond Strength of Denture Base Resin to Base Metal Alloy after Electrolytic Etching and Laser Etching: An In Vitro Study. Journal of International Oral Health. 2015;7:100- 10.

6. Sasaki M, Yasuda N, Mogi T, Ai M. Influence between metal and resin on the finishing line of cobalt-chromium denture. Part 3. Studies on finishing line structure. J Jpn Prosthodont Soc. 1994; 38:191-7.

7. Zurasky JE, Duke ES. Improved adhesion of denture acrylic resins to base metal alloys. The Journal of Prosthetic Dentistry. 1987;57:520-4.

8. Henriques B, Sampaio M, Buciumeanu M, Souza JCM, Gomes JR, Silva F, et al. Laser surface structuring of Ti6Al4V substrates for adhesion enhancement in Ti6Al4VPEEK joints. Materials Science and Engineering: C. 2017;79:177-84.

9. Henriques B, Fabris D, Souza JCM, Silva FS, Carvalho Ó, Fredel MC, et al. Bond strength enhancement of zirconiaporcelain interfaces via Nd: YAG laser surface structuring. Journal of the Mechanical Behavior of Biomedical Materials. 2018;81:161-7.

10. Maiman TH. Stimulated optical radiation in ruby. Nature. 1960;23:493-8.

11. Li R, Ren Y, Han J. Effects of pulsed Nd: YAG laser irradiation on shear bond strength of composite resin bonded to porcelain. West China Journal of Stomatology. 2000;18:377-9.

12. Murray AK, Attrill DC, Dickinson MR. The effects of XeCl laser etching of Ni-Cr alloy on bond strengths to composite resin: a comparison with sandblasting procedures. Dental Materials. 2005;21:538-44.

13. Kim J-T, Cho S-A. The effects of laser etching on shear bond strength at the titanium ceramic interface. The Journal of Prosthetic Dentistry. 2009;101:101-6.

14. Yilmaz A, Akyil MÅ, Hologlu B. The effect of metal primer application and Nd: YAG laser irradiation on the shearbond strength between polymethyl methacrylate and cobaltchromium alloy. Photomedicine and Laser Surgery. 2011;29:39-45.

15. Matsuda Y, Yanagida H, Ide T, Matsumura H, Tanoue N. Bond strength of poly (methyl methacrylate) denture base material to cast titanium and cobalt-chromium alloy. Journal of Adhesive Dentistry. 2010;12:213-5.

16. Al Jabbari YS, Zinelis S, Al Taweel SM, Nagy WW. The Effect of Artificial Aging on The Bond Strength of Heat- 
activated Acrylic Resin to Surface-treated Nickelchromium-beryllium Alloy. The Open Dentistry Journal. 2016;10:25-9.

17. Alageel O, Abdallah M-N, Luo ZY, Del-Rio-Highsmith J, Cerruti M, Tamimi F. Bonding metals to poly (methyl methacrylate) using aryldiazonium salts. Dental Materials. 2014;31:105-14.

18. Mahouche-Chergui S, Gam-Derouich S, Mangeney C, Chehimi MM. Aryl diazonium salts: a new class of coupling agents for bonding polymers, biomacromolecules and nanoparticles to surfaces. Chemical Society Reviews. 2011;40:4143-66.

19. Aazad AM, Shetty P, Bhat S, Joseph M. Comparative evaluation of tensile bond strength of denture base resins to surface pretreated cobalt chromium base metal alloys--an in vitro study. Indian Journal of Dental Research: official publication of Indian Society for Dental Research. 2001;12:159-65.

20. Abdo RM. The Effect of Bonding Agent on The Attachment of Acrylic Resin to Metallic Frameworks. Thesis submitted to the Faculty of Dentistry, Alexandria University 2005:513.

21. Leslie SA, Mitchell JC. Removing gold coating from SEM samples. Palaeontology. 2007;50:1459-61.

22. Kawaguchi T, Shimizu H, Lassila LVJ, Vallittu PK, Takahashi Y. Effect of surface preparation on the bond strength of heat-polymerized denture base resin to commercially pure titanium and cobalt-chromium alloy. Dental Materials Journal. 2011;30:143-50.

23. Ikeda T, Wakabayashi N, Ona M, Ohyama T. Effects of polymerization shrinkage on the interfacial stress at resinmetal joint in denture-base: A non-linear FE stress analysis. Dental Materials. 2006;22:413-9.

24. Pesun S, Mazurat RD. Bond strength of acrylic resin to cobalt-chromium alloy treated with the Silicoater MD and Kevloc systems. Journal-Canadian Dental Association. 1998;64:798-802.

25. Van Meerbeek B, Peumans M, Poitevin A, Mine A, Van Ende A, Neves A, et al. Relationship between bondstrength tests and clinical outcomes. Dental Materials. 2010;26:e100-e21.

26. Barclay CW, Spence D, Laird WRE, Marquis PM, Blunt L. Micromechanical versus chemical bonding between Co-Cr alloys and methacrylate resins. Journal of Biomedical Materials Research Part B: Applied Biomaterials. 2007;81:351-7.

27. Kermabon-Avon G, Bressy C, Margaillan A. Statistical design strategies to optimize properties in miniemulsion polymerization of methyl methacrylate. European Polymer Journal. 2009;45:1208-16.

28. Silikas N, Al-Kheraif A, Watts DC. Influence of P/L ratio and peroxide/amine concentrations on shrinkage-strain kinetics during setting of PMMA/MMA biomaterial formulations. Biomaterials. 2005;26:197-204.

29. Yucel MT, Kilic I, Okutan Y, Tobi ES, Kilic HS, Kepceoglu A, et al. Effect of different surface treatments on the shear bond strength of resin cement to zirconia ceramic and metal alloy. Journal of Adhesion Science and Technology. 2018;5:1-12.
30. Caglar I, Ates SM, Yesil Duymus Z. An in vitro evaluation of the effect of various adhesives and surface treatments on bond strength of resin cement to polyetheretherketone. Journal of Prosthodontics. 2018;4:78-90.

31. Murray AK, Attrill DC, Dickinson MR. Qualitative assessment of surface topography of $\mathrm{XeCl}$ laser etched NiCr alloy. Dental Materials. 2005;21:837-45.

32. Cho S-A, Jung S-K. A removal torque of the laser-treated titanium implants in rabbit tibia. Biomaterials. 2003;24:4859-63.

33. Wagner WC. A brief introduction to advanced surface modification technologies. The Journal of Oral Implantology. 1992;18:231-5. 